\title{
The concept of population in clonal organisms: mosaics of temporally colonized patches are forming highly diverse meadows of Zostera marina in Brittany
}

\author{
R. Becheler ${ }^{1}$, O. Diekmann ${ }^{2}$, C. Hily ${ }^{3}$, Y. Moalic ${ }^{1}$ and S. Arnaud-Haond ${ }^{1,2,{ }^{*}}$ \\ ${ }^{1}$ Ifremer, Laboratoire Environnement Profond, Centre de Brest BP70, 29280 Plouzané, France \\ ${ }^{2}$ CCMAR, CIMAR-Laboratório Associado, University of Algarve, Campus de Gambelas, 8005-139 \\ Faro, Portugal \\ ${ }^{3}$ LEMAR, Institut Universitaire Européen de la Mer, Université Occidentale de Bretagne, 29280 \\ Plouzané, France \\ *: Corresponding author : S. Arnaud-Haond, Fax: +33/0298224757, email address : sarnaud@ifremer.fr
}

\begin{abstract}
:
Seagrasses structure some of the world's key coastal ecosystems presently in decline due to human activities and global change. The ability to cope with environmental changes and the possibilities for shifts in distribution range depend largely on their evolvability and dispersal potential. As large-scale data usually show strong genetic structure for seagrasses, finer-grained work is needed to understand the local processes of dispersal, recruitment and colonization that could explain the apparent lack of exchange across large distances. We aimed to assess the fine-grained genetic structure of one of the most important and widely distributed seagrasses, Zostera marina, from seven meadows in Brittany, France. Both classic population genetics and network analysis confirmed a pattern of spatial segregation of polymorphism at both regional and local scales. One location exhibiting exclusively the variety 'angustifolia' did not appear more differentiated than the others, but instead showed a central position in the network analysis, confirming the status of this variety as an ecotype. This phenotypic diversity and the high allelic richness at nine microsatellites (2.33-9.67 alleles/locus) compared to levels previously reported across the distribution range, points to Brittany as a centre of diversity for $Z$. marina at both genetic and phenotypic levels. Despite dispersal potential of several $100 \mathrm{~m}$, a significant pattern of genetic differentiation, even at fine-grained scale, revealed 'genetic patchiness'. Meadows seem to be composed of a mosaic of clones with distinct origins in space and time, a result that calls into question the accuracy of the concept of populations for such partially clonal species.
\end{abstract}

Keywords: clonality $\bullet$ dispersal $\bullet$ ecotype $\bullet$ network analysis $\bullet$ population $\bullet$ Zostera marina 


\section{INTRODUCTION}

Seagrasses are the structural basis of key coastal marine ecosystems (Orth et al. 2006) supporting high biodiversity and biomass (Orth et al. 1984). These ecosystems provide a great number of goods and services, including primary production, the supply of food for megaherbivores, habitats for resident faunas and stabilization of sediments (Hemminga \& Duarte 2000). Many of these are experiencing a decline on a worldwide scale, probably due to anthropogenic disturbances and climate change (Waycott et al. 2009). The ability of these species, and of the ecosystems they supply, to survive future environmental changes may largely depend on their genetic adaptability (Booy et al. 2000; Frankham 2005). The attempt to predict, and possibly prevent, changes in the geographical pattern of persistence, local extinction or range shifts should be based on a good understanding of the implications of genetic diversity for the resistance and resilience of local populations, as well as on reliable estimates of dispersal among geographic areas. Dispersal is likely to determine the balance between migration-drift and local adaptation, and in turn the likelihood of meadows to survive or to be naturally recolonized if locally extinct.

In temperate latitudes, meadows are generally monospecific, and the dominant family is Zosteraceae, which contains five monophyletic species, including the eelgrass Zostera marina. This species is widely distributed in the northern hemisphere, and present in the Pacific and Atlantic Oceans, as well as in the Mediterranean and Black Seas. It is the dominant seagrass on the coasts of Brittany (France) where it shares (Den Hartog \& Hily 1997) a dominant role with algae in structuring one of the most important coastal ecosystems and providing habitat for a large number of species (Hily \& Bouteille 1999).

Eelgrass reproduces sexually through the production of propagules, and clonally through 
the vegetative production of ramets via rhizome elongation. This partial clonality has multiple biological and methodological implications. In particular, estimations of diversity in these populations require distinction between genet (genetic individuals, where all tissue has originated from one zygote; Eriksson, 1993) and ramet (a potentially independent part of the genet that often represents the sampling unit; Eriksson 1993; Arnaud-Haond et al. 2007a). Clonal diversity has been shown experimentally to enhance resistance and resilience of experimental quadrats of Z. marina to perturbations (Ehlers et al. 2008; Hughes \& Stachowicz 2004; Reusch et al. 2005). If these experimental results are extrapolated to natural populations (Arnaud-Haond et al. 2010; Hughes \& Stachowicz 2009), the level of clonal diversity is found to be associated with an enhanced resistance to environmental perturbations. A large biogeographic survey (Olsen et al. 2004) reported moderate to high values of clonal richness for two locations in Brittany, (Carantec: 0.54; Morgat: 0.90).

Genetic diversity, i.e. the allelic richness and/or heterozygosity observed in meadows, is influenced by numerous factors, such as effective population size, spatial pattern of dispersal and recruitment success of immigrant propagules (dependent on competition and local adaptation) and the biogeographical history of populations (Olsen et al. 2004). At the scale of its entire distribution, these authors reported an allelic diversity hotspot for Z. marina in the North Sea-Wadden Sea region, where populations are characterized by high allelic richness. This region is also a diversity hotspot for Z. noltii (Coyer et al. 2004). In contrast, East Atlantic meadows of $Z$. marina, including the two locations in Brittany studied here, exhibited much lower levels of allelic richness, suggesting a narrower adaptive potential. Yet those two particular samples from Brittany showed distinct levels of clonal and allelic richness, calling for further analysis of the spatial variability and fine-grained pattern of clonal and genetic composition that had thus far only been performed on samples from the Baltic Sea. 
Moreover, the possibility of heterogeneity in intra-meadow clonal and genetic composition had never been explored, to the best of our knowledge, in such phylogeographic analyses on seagrasses (Alberto et al. 2008; Arnaud-Haond et al. 2007b; Coyer et al. 2004; Olsen et al. 2004). Some benthic marine invertebrates show contrasted patterns of genetic diversity and structure at a very fine-grained scale (Arnaud-Haond et al. 2008; Johnson \& Black 1984), likely due to the chaotic nature of dispersal in the marine environment (Roughgarden et al. 1988). Given the large-scale dispersal potential of most marine angiosperms through seed or shoot dispersal, combined with their benthic nature and extensive clonal propagation once settled, a similar phenomenon might occur in seagrass meadows.

Finally, the occurrence of the variety 'Z. angustifolia', already described in the UK, has also been seen in Brittany, particularly in the Morbihan Gulf (France, REBENT). Whether this particular morph corresponds to a distinct species, as suggested by some authors (Percival et al. 1996; Provan et al. 2008), or to an ecotype (De Heij \& Nienhuis 1992; Den Hartog 1970), is still unknown as no genetic studies have been reported so far that address this issue. This topic is of central importance for understanding gene flow and local adaptation processes in $Z$. marina meadows across its distribution range.

In the present work, we used nine microsatellites to (i) identify the particular morph " $Z$. marina v. angustifolia”, in order to test its status as a genetically distinct taxon or ecotype; (ii) investigate the genetic diversity and genotypic structure along the coasts of Brittany; (iii) test for the importance of fine-grained variation (intra meadow versus regional scale) of these characteristics; and (iv) assess the dispersal potential at local (i.e. fine-grained) and regional scales. 


\section{MATERIAL AND METHODS}

\section{Sample collection}

Eelgrass samples were collected in February to April 2009 from 7 intertidal meadows along the coast of Brittany (Fig. 1), stretching from Saint-Malo to Arradon. Distances between meadows ranged from 33 km (Molène - Roscanvel) to 442 km (Arradon - Saint-Malo). For each location, two $20 * 30 \mathrm{~m}$ quadrats separated by several tens of meters were chosen, located in continuous parts of the meadow monitored as part of the REBENT survey (REseau BENThique, a French network specialized in the survey of major coastal ecosystems including eelgrass meadows; www.rebent.org). Approximately 35 sampling units (SU) were collected according to randomly drawn coordinates (Table 1). In Molène, due to high patchiness of the meadow, only one quadrat was sampled, with 20 su according to random coordinates and the 12 more collected at haphazardly in the patchy end of the meadow. Annual observations from REBENT indicated Saint-Malo as one of the sites where the variety "angustifolia" is observed across years. The field observations indeed showed the typical Z. marina v. angustifolia variety in both quadrats of this meadow, with dwarf shoots exhibiting narrow leafs almost comparable in size and shape to the dwarf Z. noltii.

The base of each leaf bundle, including the shoot apical meristem, was preserved in silica crystals until DNA extraction.

$$
\text { DNA extraction, isolation, microsatellite and ITS amplification and loci scoring }
$$

\footnotetext{
The Fast DNA®SPIN kit for soil was used for DNA extraction according to the protocol
} 
provided by the manufacturer (MP Biomedicals, France). Nine microsatellite loci (Genbank accession numbers: AJ009899, AJ009901, AJ009902, AJ009905 and AJ249303 to AJ249307; Reusch et al. (1999) Reusch (2000)) were PCR-amplified using fluorescently labeled primers (GA12, GA19, GA20, GA17D, GA16, GA2, GA23, GA35 and GA17H). PCR products were visualized using an ABI-3100 FNVR automated sequencer (Applied Biosystems) and scored using STRand software (http://www.vgl.ucdavis.edu/informatics/strand.php). A double blind reading was made by two different users and gels were re-scored when discrepancies were recorded.

To standardize the samples at 30 individuals before estimations of clonal and genetic composition, excess individuals were removed at random.

To test whether the variety "angustifolia" corresponded to a species or to an ecotype, we also compared sequences of ITS markers (1100 bp) of two samples exhibiting the typical morphology of the variety "angustifolia" (Saint-Malo) with two samples from Arradon and from Arcouest locations exhibiting the typical morphotype of Z. marina. ITS-PCRs were performed using the universal primers Jo6 and TW5 (White et al., 1990 in Diekmann et al. 2001).

\section{Genetic and clonal data analysis}

In order to identify genetic individuals (i.e. to discriminate genets from ramets on the basis of their Multi Locus Genotype: MLG), we used a "barcoding" type approach based on 9 microsatellite loci.

For clonal organisms, two questions must be answered: (i) do all the replicates of the same MLG really belong to the same genet (i.e. are they all issued from the same sexual reproduction event)? and (ii) does each distinct MLG really belong to a distinct genet? 
To answer the first question, when the same MLG is encountered $\mathrm{n}$ times in a sample of $\mathrm{N}$ sampling units, the probability that the identical MLGS originate from different sexual reproductive events ( $\mathrm{p}_{\text {sex }}$ ) should be assessed (Arnaud-Haond et al. 2007a). Below a threshold value fixed at 0.01 , identical MLGs may be considered as belonging to the same genet. Estimates of $\mathrm{p}_{\text {sex }}$ are derived on the basis of allelic frequencies estimated using the round robin method (Parks \& Werth 1993), with a sub-sampling approach to limit the overestimation of the rare alleles. Allelic frequencies for each locus are estimated on the basis of a sample pool composed of all the MLGs discriminated, while excluding the loci for which allelic frequency is estimated. This procedure is repeated for each locus, taking into account Wright's inbreeding coefficient estimated after the exclusion of identical MLG (Young et al. 2002).

Once the clonal membership of identical MLG is ascertained using $\mathrm{p}_{\mathrm{sex}}$, slightly distinct MLGs belonging to the same genet may, nevertheless, still occur in the dataset, either due to the existence of somatic mutation or scoring errors (Arnaud-Haond et al. 2007a; Douhovnikoff \& Dodd 2003). If ignored, this would lead to an overestimation of the number of clones in the sample analyzed. The two-step approach proposed by Arnaud-Haond et al. (2007a) was applied to test whether these slightly distinct (at one or two loci) MLGs belong to the same genet by: (i) screening each MLG pair presenting an extremely low distance; (ii) using $\mathrm{p}_{\mathrm{sex}}$ on the set of identical loci in order to estimate the probability that the slightly distinct MLG could actually be derived from distinct reproductive events. When $\mathrm{p}_{\mathrm{sex}}$ is lower than 0.01 , the two identical MLG can be considered to belong to the same genet or Multi Locus Lineage (MLL; Arnaud-Haond et al. 2007a).

Estimates were calculated using the software GENCLONE 2.1 (Arnaud-Haond \& Belkhir 2007).

For each quadrat, clonal diversity was estimated by: 
where $\mathrm{G}$ is the number of MLLs in the sample and $\mathrm{N}$ is the number of sUs analyzed, as recommended by Dorken \& Eckert (2001) and Arnaud-Haond et al. (2005). The minimum value for clonal diversity in a monoclonal stand is always 0 , independent of sample size, and the maximum value is still 1 when each analyzed sample corresponds to a distinct MLL. The complement of the Simpson index (Pielou 1969) for genotypic diversity in each quadrat, representing the probability of encountering distinct MLLs when randomly taking two sampling units, was estimated as:

$$
D=1-\sum_{i=1}^{G} p_{i}^{2}
$$

where $\mathrm{p}_{i}{ }^{2}$ is the frequency of the $\mathrm{i}^{\text {th }}$ MLL (its estimation is given by: $\mathrm{p}_{\mathrm{i}}{ }^{2}=\left[\mathrm{n}_{\mathrm{i}}\left(\mathrm{n}_{\mathrm{i}}-1\right)\right] /[\mathrm{N}(\mathrm{N}-$ 1)] where $N$ is the number of ramets sampled and $n_{i}$ is the number of sample units sharing the $\mathrm{i}^{\text {th }}$ MLL). Moreover, we estimated the Simpson's evenness index to describe clonal equitability:

$$
E D^{*}=\frac{\left(D-D_{\min }\right)}{\left(D_{\max }-D_{\min }\right)}
$$

with $\mathrm{D}_{\min }$ and $\mathrm{D}_{\max }$ being the approximate minimum and maximum values of Simpson's complement index given the sample size $\mathrm{N}$ and the sample clonal richness $\mathrm{G}$, estimated as:

$$
D_{\text {min }}=\left[\frac{(2 N-G) \times(G-1)}{N^{2}}\right] \times \frac{N}{(N-1)} \text { and } D_{\max }=\frac{(G-1)}{G} \times \frac{N}{(N-1)}
$$

The $\beta$ of the Pareto distribution, representing the negative slope of the power law usually describing the distribution of ramets into groups of clonal size (Arnaud-Haond et al. 2007a), was also estimated as this metric seems less sensitive than other estimators to the relative density of sampling units versus shoots in the sampled meadow. All clonal diversity and structure parameters were calculated with GENCLONE 2.1 (Arnaud-Haond \& Belkhir 2007). 
A single copy of each discriminated MLL was retained in the dataset used to assess genetic diversity and structure. Genetic diversity within quadrats was estimated as the mean number of alleles per locus $(\hat{\mathrm{A}})$, with observed $\left(\mathrm{H}_{\mathrm{O}}\right)$ and unbiased $\left(\mathrm{H}_{\mathrm{E}}\right)$ multilocus heterozygosity (Nei 1978). Linkage disequilibrium was tested according to Black \& Krafsur (1985). A permutation procedure (1000 permutations) was used to test whether a particular estimate of the overall inbreeding coefficient $\left(\mathrm{F}_{\mathrm{IS}}\right)$ or linkage disequilibrium was significantly different from $0(\mathrm{p}<0.01)$

Genetic structure among populations was estimated with $\theta$ (Weir \& Cockerham 1984). A Mantel test including geographical distances among populations was carried out to test for the two dimensional “Isolation By Distance” (IBD) model (Rousset 1997). These parameters were estimated using GENETIX (Belkhir et al. 2004).

At the within-quadrat level, autocorrelation analyses were performed to test for the existence of restriction to dispersion at the intra-meadow scale, and to estimate the extent of clonality. We used the kinship estimator coefficient of Ritland $\left(\mathrm{F}_{\mathrm{ij}}\right)$ as a genetic relatedness statistic (Ritland 1996). We performed regression analyses of mean $F_{i j}$ against the $\log _{e}$ of mean geographic distance, within each distance class. This allowed us to test the adequacy of IBD models in each quadrat. The autocorrelation analyses were performed using Ritland's coefficient of kinship: (i) first including all sus, where it is mostly influenced by the spatial extent of clones/clonal lineages (i.e. the genetic neighborhood of sus belonging to the same MLL) and (ii) using permutations (1000) in order to include only one ramet (and one of the possible corresponding coordinates, randomly chosen for each permutation step) from each genet at each permutation, in order to examine the dispersion through sexual propagules. The slopes of regressions (b) allowed us to calculate the Sp statistic (Vekemans \& Hardy 2004). 
This statistic corresponds to the spatial autocorrelation profile, varying from 0 (no limitation to gene dispersal at the scale of the sampling) to $+\infty$ (theoretical case, where the structure is maximal). Its equation is the following:

$$
S p=\frac{-b}{1-\hat{F}_{(1)}}
$$

with $\hat{F}_{(1)}$ the kinship value for the first distance class. Autocorrelation parameter estimations were performed with GENCLONE 2.1 (Arnaud-Haond \& Belkhir 2007).

The clonal subrange $\mathrm{CR}$ was estimated for each quadrat to describe the spatial components of the clonal population. It corresponds to the minimal estimates of the maximum distance between two identical genotypes belonging to the same clone, in meters, and is determined as the distance for which the probability of clonal identity becomes null (Alberto et al. 2005; Harada et al. 1997).

\section{Network analysis}

Network analysis is a graphic, holistic and non-parametric method that has proven useful in the illustration and analysis of population structure (Fortuna et al. 2009; Rozenfeld et al. 2007; Rozenfeld et al. 2008). In this study, networks based on genetic distances were used (i) to ascertain the relative position of the variety "angustifolia" (sampled in Saint-Malo) against other sampling locations, in a global network including all genets from all locations, and (ii) to illustrate the distribution of genetic distances at a finer scale (i.e. among genets from distinct quadrats within sampling locations). Individual-based networks of genetic distances were built at the global scale (all quadrats) and at local scales (for each sampling locality), illustrating the connection of some genets (agents) depending on their genetic distance (link). The distances used have proven successful in assigning unknown individuals to their correct subpopulations 
(Estoup et al. 1995) and is classically known as the "Shared Allele Distance”, (Chakraborty \& Jin 1993), although it actually reflects the proportion of non shared alleles:

$$
D_{S A_{I}}=1-\frac{\sum u S}{2 \mathrm{u}}
$$

with $\mathrm{S}$ the number of shared alleles and u the number of loci. $D_{S A_{I}}$ spans from 0 to 1 .

Networks are built including links for all distances, which are subsequently removed in decreasing order, until reaching the effective percolation point, Dpe (Rozenfeld et al. 2007; Stauffer \& Aharony 1994), below which the network fragments into small clusters. This phenomenon can be interpreted as the first level of limitation to gene flow. The precise calculation of the Dpe is made with the standard methodology for a finite system, proposed by Stauffer \& Aharony (1994) and consisting of calculating the average cluster size excluding the largest one:

$$
\langle S\rangle=\frac{1}{N} \sum_{s<S \max } s^{2} n_{s}
$$

as a function of the last distance value removed. $N$ is the total number of nodes not included in the largest cluster and $n_{\mathrm{s}}$ is the number of clusters containing $s$ nodes. Once this effective percolation threshold is reached, we analyzed the network topology and its characteristics (Table 4; Fig. 4).

\section{Global and local property estimates of the network}

The clustering coefficient $C_{i}$ of the node $i$ is the ratio between the number of existing links with the maximal number of potential links within the cluster. It is defined as:

$$
C i=\frac{E i}{E i^{(\max )}}=\frac{2 E i}{k i(k i-1)}
$$


with $E i$ the number of links existing among the neighbors of the node $i$, and the degree $k i$

282

283

284

285

286

287

288

289

290

291

292

293

294

of a given node $i$ the number of other nodes linked to it. The clustering coefficient of the whole network $<C C>$ is defined as the average of all individual clustering coefficients in the system. The clustering of nodes is interpreted as the existence of hierarchical substructure, with clusters of genets within which members are more closely related to one another than they are to other genets outside the particular cluster.

The betweenness centrality (Freeman 1977) of node $i, b c(i)$, is the fraction of shortest paths between pairs of nodes that pass through node $i$. Let $\sigma_{\mathrm{st}}$ denote the number of shortest paths connecting nodes $s$ and $t$ and $\sigma_{\mathrm{st}}(i)$ denote the number of those passing through the node $i$; then:

$$
b c(i)=\sum_{s \neq t \neq i} \frac{\sigma s t(i)}{\sigma s t} .
$$

Higher values of betweenness centrality in genetic networks have been interpreted as the importance of a given agent (a population or cluster of individuals) in relaying gene flow across the system, i.e. to and from other agents (Rozenfeld et al. 2008). 


\section{RESULTS}

\section{ITS polymorphism in Z. marina and Z. marina v. angustifolia}

Of six genets from the first quadrats in Saint-Malo, Arradon and Arcouest, only two haplotypes were observed, and these differed at only one nucleotide substitution out of 1100 base pairs of ITS $1 \& 2$. This difference distinguished one genet from Arradon from the five others, which shared the most common haplotype.

\section{Clonal structure and diversity}

The clonal diversity of the 13 quadrats showed high variability both within and among locations (Table 2). The minimum values were observed in the Molène meadow and quadrat 2 at Saint-Malo $(\mathrm{R}=0.48 ; \beta=1.36$ and $\mathrm{R}=0.48 ; \beta=1.54$, respectively), whereas quadrat 1 at Roscanvel and quadrat 2 at Arcouest showed highest clonal richness $(\mathrm{R}=1.00 ; \beta \geq 4.95$ for both). Mean clonal richness was 0.72 . The largest discrepancies within location were observed in Arcouest ( $\mathrm{R}=0.62$ to 1$)$, Roscanvel ( $\mathrm{R}=0.69$ to 1 ) and Saint-Malo ( $\mathrm{R}=0.48$ to 0.62 ).

The clonal subrange was also highly variable (largest clones in quadrat 1 of the SaintMalo meadow: $\mathrm{CR}=18.61 \mathrm{~m}$; shortest clones in quadrats 1 of Roscanvel and 2 of Arcouest: $\mathrm{CR}=0.00 \mathrm{~m})$. A high within-location variability was observed here also: those quadrats with the highest clonal diversity, and therefore a minimum clonal subrange, were found sharing a site with a second quadrat ranking among the highest in terms of clonal subrange (CR $=12.04$ in quadrat 2 at Roscanvel and CR $=17.01$ in quadrat 1 at Arcouest). 

variable among locations (Table 2), mostly due to the extreme composition of Saint-Malo

Genetic composition analyzed with a single representative of each MLL was highly (heterozygosity of 0.35 and allelic richness of 2.33 in quadrat 1) and Sainte-Marguerite (heterozygosity of 0.6 and allelic richness of 9.67 in quadrat 2). The estimates appeared more stable among quadrats within these locations, as well as among the other locations, despite high variance in clonal diversity estimates, which tends to support the idea of sexual and panmictic entities in the remaining quadrats, once replicates are removed.

Similarly, departures from HWE and the occurrence of linkage disequilibrium (LD) were generally weak once replicates were removed, except for quadrat 2 in Sainte-Marguerite, showing heterozygote deficiency $\left(\mathrm{F}_{\mathrm{IS}}=0.14, \mathrm{p}<0.001\right)$ and quadrats 2 of Arcouest and 1 of Saint-Malo, with an excess of heterozygosity (respectively $\mathrm{F}_{\mathrm{IS}}=-0.12 ; \mathrm{p}<0.01$ and $\mathrm{F}_{\mathrm{IS}}=-$ $0.21 ; \mathrm{p}<0.01)$. Here most values were similar among quadrats within location except for Saint-Malo with the important heterozygote excess mentioned here in one quadrat and no significant departure observed in the other.

Slightly significant preferential matching between alleles was detected for the majority of quadrats, with 6.7 to $19 \%$ of LD values significantly different from 0 . Here again, quadrat 1 of Saint-Malo and quadrat 2 of Sainte-Marguerite departed from the average with 50 and $58 \%$ of significant values, respectively. To assess whether significant values resulted from a "locus" or "population effect”, we therefore removed these two quadrats. For each pair of loci (total of 36 pairs), no significant LD value was found for 11 pairs, 1 significant value was found for 15 pairs, 2 for 5 pairs, 3 for 4 pairs, and only the pair GA2 / GA17H showed 6 significant LD values, indicating a significant and possibly physical linkage disequilibrium between these two loci. Finally, a positive and significant relation between $\mathrm{F}_{\mathrm{IS}}$ and LD values 
was found $\left(\mathrm{R}^{2}=0.31\right.$; slope $\left.=0.25 ; \mathrm{p}=0.049\right)$ indicating that most $\mathrm{LD}$ values may be statistical and due to departure from random mating rather than to physical proximity of loci, in agreement with the lack of significant results observed in a previous study with large-scale sampling across the distribution range of the species (Olsen et al. 2004).

\section{Genetic structure among locations \& differentiation}

When the dataset was analyzed at the genet level (i.e. including only one copy of each recognized MLL), this revealed wide genetic differentiation among the 13 locations. All $F_{\mathrm{ST}}$ values per pair of sampling quadrats were significantly different from 0 ( $\mathrm{p}<0.05$; Table 3 ). The minimum value was observed between quadrats Callot 1 and Saint-Malo $2\left(\mathrm{~F}_{\mathrm{ST}}=0.039 ; \mathrm{p}\right.$ $<0.05)$ and $\mathrm{F}_{\mathrm{ST}}$ reached $0.33(\mathrm{p}<0.01)$ between Molène and quadrat 2 at Arcouest. Within locations, all quadrat pairs were also significantly different and sometimes exceeded some of the inter-location estimates. The minimum was observed among the quadrats at Roscanvel $\left(\mathrm{F}_{\mathrm{ST}}=0.019 ; \mathrm{p}<0.05\right)$ and the maximum among the quadrats at Callot $\left(\mathrm{F}_{\mathrm{ST}}=0.12 ; \mathrm{p}<0.01\right)$.

A Mantel test carried out among all pairs of populations was significant (slope : 0.04; $\mathrm{R}^{2}=$ 0.11; $\mathrm{p}<0.01$; Fig. 2), but such significance can not be interpreted as an indication of a strict IBD pattern, as it is mostly driven by the sampling scheme, which results in two clouds of dots representing the intra versus inter location distances among quadrats. No relation was observed at either of these two scales (among pairs within location: slope $=-0.19, \mathrm{R}^{2}=0.63$, n.s.; pairs among locations: slope $=-0.002, \mathrm{R}^{2}=0.004$, n.s.), suggesting that distance may not be the predominant factor acting at the regional spatial scale.

The limitation to dispersal, as estimated through autocorrelation analysis, was indeed highly variable among meadows (for an example see Fig. 3). The value of $S p$ was significantly different from 0 for four out of 13 quadrats (quadrat 1 at Arradon, $S p=0.04$, p $<0.001$; 
Arcouest $, S p=0.03, \mathrm{p}<0.001$; and Saint-Malo, $S p=0.02, \mathrm{p}<0.05$; and quadrat 1 at Roscanvel, $S p=0.02, \mathrm{p}<0.05)$.

\section{Network topology of Z. marina individuals}

The effective percolation threshold (Dpe) was seen to be about 0.45 (data not shown), below which the network lost its integrity and the clusters broke down into 2 distinct clusters. On the global network just above this percolation threshold (Fig. 4) there is a first cluster composed of genets sampled in Molène and Sainte-Marguerite (on the top left part) and a second cluster of genets sampled the other localities. Within the giant cluster above the percolation point, as well as inside this secondary cluster emerging below it, the genets from Saint-Malo have a central position, along with the highest average value of betweenness centrality $(<\mathrm{BC}>=0.0099)$ (global average value of $\mathrm{BC}$ is 0.0048 , see table 4 for network characteristics).

Network topologies at the fine-grained spatial scale (Fig. S1) revealed two clusters for each location, related to the sampling quadrats, except for Roscanvel and Sainte-Marguerite, which showed clustering values that were half those of the four other locations $(0.17$ and 0.16 respectively versus an average value of 0.32 ). It should be noted that no conclusion can be drawn about Molène as there was only one quadrat. 


\section{DISCUSSION}

Z. marina $v$. angustifolia: an ecotype rather than a protospecies?

Considered alternatively as an ecotype or as a distinct species, Z. angustifolia was first reported in the UK, the Morbihan Gulf and Arcachon Bay (France). The annual observations by the REBENT network also detected this morph at Saint-Malo over a number of years. Its predominant occurrence in spring led us to consider it as an annual variety of Z. marina (Hily, personnal observation). No differences in ITS-sequence were observed between the variety “angustifolia” (sampling units from Saint-Malo) and the typical variety of Z. marina (sUs from other locations). The occurrence of private alleles was no higher in Saint-Malo than in the other locations (only two private alleles in the first quadrat). Also, pairwise $F_{\text {ST }}$ values involving quadrats from Saint-Malo ranked among the average pairwise comparisons. Network analysis agreed with this result, showing a complete mixture of Saint-Malo MLLs with all other MLLs, and even highlighting a central position of genets from Saint-Malo (Table 4 and Fig. 5). The values of betweenness centrality also suggest a higher genetic relatedness of genets from the meadow of Saint-Malo to those of most other locations. Our data therefore support Z. marina v. angustifolia in Saint-Malo as an ecotype, rather than a distinct species.

It was not clear at this point in the analysis whether this morph with a cyclical "bloom" arose due to the annual growing of shoots from persistent rhizomes or to annual episodes of germination of dormant seeds. The former seems to be a more likely explanation, considering the limited clonal diversity, high clonal subrange and heterozygote excess observed in SaintMalo. These indices indeed tend to support the occurrence of large and persistent clones. In the neighborhood near the city (several tens of meters from the walls of Saint-Malo), the 
extreme exposure, together with a high level of local clam digging during equinox tides, suggests an increased anthropogenic influence on this meadow. The level of disturbance may therefore be high, allowing only the recruitment and persistence of specific genotypes able to cope with extreme conditions. Similarly, Diaz-Almela et al. (2007) highlighted an increase of CR in impacted populations of Posidonia oceanica, compared with reference non-impacted populations, and a higher resistance to disturbances resulting from fish-farming in meadows showing a high CR value. This suggests that large clones have a higher fitness, potentially conferring a competitive advantage for spatial colonization, and enhanced phenotypic plasticity (Diaz-Almela et al. 2007). This hypothesis is consistent with the excess of heterozygosity (in a scenario of heterosis), as well as with low clonal and allelic richness. Interestingly, Z. marina $v$. angustifolia is also generally observed in harsh conditions in the residual ponds within meadows of Z. noltii in Arcachon bay, France (Auby, personnal communication), where it is subjected to strong variations in temperature, salinity, $\mathrm{pH}$ and oxygen concentration during low tide. All these elements suggest that Z. marina $v$. angustifolia is an ecotype that is revealed above a perturbation threshold, leading to an extreme in the expression of the phenotypic plasticity of Z. marina that allows survival in such stressful and fluctuating environmental conditions. A further point of inquiry would be to compare these two types in terms of resistance to "wasting disease", a development of the slimemold-like protist Labyrinthula macrocystis in Zostera leaves at various sites (Hily et al. 2002).

\section{Clonal architecture and genetic variability.}

$$
\text { The clonal richness observed in Brittany is quite variable among sites but remains high ( } \mathrm{R}
$$


ranges from 0.48 to 1) in comparison to previous studies (Olsen et al. 2004; Reusch et al. 1999). These values are comparable to those observed in the populations representing Brittany in the large biogeographic survey performed by Olsen et al. (2004) where the neighboring populations of Carantec and Morgat had R values of 0.54 and 0.90, respectively. The heterogeneity of clonal richness values for locations in Brittany indicates a notable variation in the pattern of investment in sexual versus clonal reproduction at the regional scale.

Contrastingly, estimates of allelic diversity in the present study are strikingly different from those found by Olsen et al. (2004). A much higher allelic richness was consistently observed, ranging from 2.33 (quadrat 1 in Saint-Malo) to 9.67 (quadrat 2 in SainteMarguerite) alleles/locus (Table 2). Allelic richness evidenced here is comparable to, or even double, the highest values reported in the Wadden Sea (4.10 alleles per locus) that led these previous authors (Olsen et al. 2004) to consider this region as a hotspot of diversity for the species. The values are also at least comparable to, and sometimes strikingly higher than, those observed in the supposed center of origin located in the Northern Pacific (the mean of $\hat{A}$ for this region reaches 5.89; from Olsen et al. 2004). The Wadden Sea-North Sea region exhibits a linear coastal distance equivalent to Brittany. Such a difference could be due to sampling strategy and scale, as the authors Olsen et al. (2004) took samples according to linear transects, a strategy that has been shown to be more prone to overestimate than underestimate diversity (Arnaud-Haond et al. 2007a). The higher values, which were observed consistently here, may therefore be attributable to the larger number of sampling locations analyzed. The sampling effort made by Olsen et al. (2004) was indeed greater in the region of the Wadden Sea (nine sampling areas) than in Brittany (two sampling areas), for which only one meadow was studied for allelic richness, potentially meaning that the sample in this previous study was not representative of the meadows at the scale of the Brittany coasts. 
These new results reveal a hotspot of Z. marina genetic diversity in Brittany compared with other populations over the distribution range as a whole. Moreover, the discrepancy with the first estimates obtained from the neighboring location of Morgat points toward a possibly significantly heterogeneous distribution of genetic polymorphism at the regional scale. This was further confirmed by analyzing the genetic structure at both regional and fine-grained spatial scales.

\section{Mosaic pattern of genetic differentiation at regional and local scales}

A rather highly structured pattern was revealed at both regional and fine-grained spatial scales. This significant and generalized differentiation was consistent even at the fine-grained spatial scale, among quadrats separated by less than $100 \mathrm{~m}$, although these values tended to be smaller than those observed among locations (Table 3; Fig. 2). This was confirmed by network analysis, which showed the occurrence of two clusters in each location, corresponding to the two quadrats, except in Roscanvel and Sainte-Marguerite. $\mathrm{F}_{\mathrm{ST}}$ values among quadrats agreed with this finding as they were also the smallest in these two locations. These results suggest a strong limitation to dispersal without a real pattern of gradual IBD, as shown by the lack of significance of the Mantel test at the regional scale.

Spatial autocorrelation analysis at the local scale allows a quantitative estimation of the spatial scale over which clonality affects the SGS (spatial genetic structure), as autocorrelograms performed at the ramet-level and at the MLL-level merge at the distance corresponding to the clonal subrange (Alberto et al. 2005). In agreement with the patterns of high SGS obtained when including all sampling units, the clonal subranges observed in SaintMalo, Arradon, Roscanvel and Arcouest (Table 2) provide a minimal estimate of ten or 
possibly several tens of meters, as these estimates are confined to our sampling areas. This suggests that clonal propagation via rhizomatic elongation accounts for dispersal at the scale of up to several tens of meters, as previously reported for Cymodocea nodosa (Alberto et al. 2005) Z. noltii (Ruggiero et al. 2005) and Posidonia oceanica (Arnaud-Haond et al. 2007b).

In the case of seagrasses, two modes of dispersal exist besides strict clonal elongation: (i) long distance dispersal via unrooted shoots, in species such as eelgrass that have easily breaking rhizomes (Hall et al. 2006; Harwell \& Orth 2002; Orth et al. 2006) when exceptional climatic events such hurricanes possibly favor long distance dispersal (Kendall et al. 2004); and (ii) medium distance dispersal via seeds (Orth et al. 2006), with the formation of gas bubbles that adhere to the seed coat of Zostera sp, giving buoyancy (Churchill et al. 1985). These authors followed drifting seeds and reported a dispersal that may exceed $200 \mathrm{~m}$, large enough to encompass distances similar to those among neighboring quadrats.

Considering these rather large estimates of dispersal potential and the lack of limitation to gene flow evidenced in 9 quadrats, a relative genetic homogeneity may be expected at the local scale. Yet, SGS is detected in 4 quadrats and the genetic differentiation among quadrats of the same location is significant (Table 3) and appears clearly in network analysis (Fig. S1). Such a combination of relatively high dispersal potential and stronger or similar genetic differentiation at the very fine spatial scale compared to the regional one was previously described as the paradox of the chaotic genetic patchiness, and the pattern has been extensively reported for marine benthic invertebrates (Arnaud-Haond et al. 2008; Edmands et al. 1996; Johannesson et al. 1995; Johnson \& Black 1982; Johnson et al. 1993; Watts et al. 1990), and fishes (Doherty et al. 1995; Hedgecock et al. 1994; Lacson \& Morizot 1991). This pattern of genetic mosaic at both temporal and spatial scales may be explained by several hypotheses. Distinct origin or differential survivorship of recruits, as well as the "sweepstake" 
hypothesis based on a differential reproductive success leading to instantaneous genetic drift (Hedgecock 1994), have been proposed. In the case of Z. marina, which is also a partially clonal species, other factors linked to the specific pattern of temporal recruitment and clonal growth are likely to be involved.

\section{Recruitment dynamics and the concept of population}

According to our results, dispersal does not balance the effect of genetic drift in eelgrass meadows. Three explanations can be advanced for this, the first being that (i) the hypotheses on which the estimates of autocorrelation patterns are based are not met, potentially leading to an overestimation of the dispersal potential. For example, the dispersion is assumed to be isotropic (i.e. equivalent in all directions of 2D space); this is a large assumption, particularly in coastal environments where current regimes are highly complex (Siegel et al. 2003). In cases where the conditions required to interpret spatial autocorrelation are met, this apparent discrepancy between expected and realized dispersal may be explained by (ii) low propagule production. This is not in agreement with the extreme clonal richness observed, which reveals an important implication of sexual reproduction in the quadrats of Roscanvel, Arcouest and Sainte-Marguerite. The third hypothesis (iii) is that of low recruitment success of dispersed propagules, possibly due to spatial competition exerted by already-established clones against drifting immigrant propagules. This hypothesis is consistent with previous studies, showing that recruitment in the sea may follow a chaotic distribution (Roughgarden et al. 1988) and that the more impacted areas in seagrass meadows (i.e. a lower density of shoots) exhibit greater recruitment success, probably due to a decrease in intraspecific competition (Reusch 2006). The influence of the outcompetition of migrants by some fitter clones is also supported 
by the observation of the highest level of clonal richness in the very recently (re)colonized meadow of Sainte-Marguerite.

Two dynamic strategies have been proposed for the settlement and growth of clonal plant meadows (Eriksson 1993): Initial Seedling Recruitment (ISR) and Repeated Seedling Recruitment (RSR). The colonization of an area results either mostly from the recruitment of an initial cohort occupying space through clonal growth (ISR) or from continuous colonization of patches (RSR). For a low level of environmental and demographic fluctuations, the predominant strategy may be ISR, due to the advantage for a seedling to be the first arrived and to acquire "strength in number”" by growing ramets to colonize space through clonal growth before another new recruit arrives. In this case of stable environmental conditions, and thereby demographic conditions, relatively low clonal diversity may also result from competitive exclusion of initially-settled clones, as suggested for species coexistence models (Huston 1979) and in the case of the dynamics of Posidonia oceanica meadows (Arnaud-Haond et al. 2010). For an intermediate level of environmental and demographic fluctuations, which reduces the intensity of competitive exclusion, the number of free microsites favors the settlement of new recruits, thereby allowing the turn-over of patches and enhancing genotypic diversity, as described in the experimental approach by Reusch et al. (2006). In such cases, the pattern of highest clonal diversity, and probably lowest genetic structure, would reveal the tuning of dynamic strategy toward RSR.

As for Z. marina, the range of clonal and genetic diversities at the regional scale therefore suggests that both strategies may apply in variable proportions depending on both the time elapsed since the last colonization and the levels of periodic disturbance in the meadows studied. As suggested for Posidonia oceanica (Arnaud-Haond et al. 2007b), the heterogeneity of spatial and temporal patterns demonstrated here highlight a potentially serious limitation of 
the use of genetic differentiation as a tool to predict recolonization potential. Such results mean we should be cautious about drawing conclusions from genetic data alone in the absence of further ecological information about local adaptation and/or intra specific competition for space for example.

Finally, according to the genetic definition, the genetically differentiated quadrats of $Z$. marina would not be considered as belonging to the same population. Yet the pattern reported here leads us to question whether two quadrats belonging to the same continuous meadow at a distance of a few meters should be considered as belonging to distinct populations. This population genetic concept was initially developed for species with exclusively sexual reproduction and may not be relevant for clonal organisms, as suggested by Bahri et al. (2009). The ecological population as defined by Camus \& Lima (2002) (“a group of individuals of the same species that live together in a area of sufficient size to permit normal dispersal and/or migration behaviour and in which numerical changes are largely determined by birth and death processes"), based on their discrete distribution, may be a more objective concept for application to clonal organisms. It should however be noted that, in order to be meaningful in an evolutionary sense, such a concept would rely on the assumption that distance and fragmentation are the main proxies for assessing the efficiency of gene flow.

\section{Conclusion}

This is, to our knowledge, the first time that the detailed screening of within-meadow variance in clonal and genetic composition and differentiation has been performed. This work reveals: 
High heterogeneity of clonal and genetic diversities at the regional scale, and the

580

581 possibility that Brittany (France) could be considered as a hotspot for the genetic diversity of Z. marina at the scale of the entire species distribution range;

- $\quad$ Strong genetic structure at regional scales revealing dispersal limitations that could potentially influence the future of Z. marina populations;

- $\quad$ Mosaic structure (genetic patchiness) at the local scale, supporting a Repeated Seedling Recruitment strategy that is likely driven by perturbations opening windows for recruitment;

- $\quad$ Large phenotypic plasticity, allowing Zostera development in a wide range of environmental conditions. As our results confirm the hypothesis that Z. marina v. angustifolia is an ecotype, this phenotypic plasticity is probably characteristic of highly stressful environments.

\section{Acknowledgements}

We wish to thank Olivier Mouchel for help with sampling and laboratory work, as well as Licinia Gouveia and the sequencing service in CCMar, particularly Xana Ramos, for the genotyping. We are also grateful to Helen Mc Combie for help with the English and editing of this manuscript. This work was supported by the Portuguese Fundacao para a Ciencia e a Technologia and Fondo Europeo de Desarrollo Regional (FEDER) through project DIVSTAB-(POCI 2010) and the European Commission through the NEST-Complexity project EDEN (043251), and benefited from the survey of the REBENT network (Ifremer). 


\section{References}

Alberto F, Gouveia L, Arnaud-Haond S, et al. (2005) Within-population spatial genetic structure, neighbourhood size and clonal subrange in the seagrass Cymodocea nodosa. Molecular Ecology 14, 2669-2681.

Alberto F, Massa S, Manent P, et al. (2008) Genetic differentiation and secondary contact zone in the seagrass Cymodocea nodosa across the Mediterranean-Atlantic transition region. Journal of Biogeography 35, 1279-1294.

Arnaud-Haond S, Alberto F, Teixeira S, et al. (2005) Assessing genetic diversity in clonal organisms: Low diversity or low resolution? Combining power and cost efficiency in selecting markers. Journal of Heredity 96, 434-440.

Arnaud-Haond S, Belkhir K (2007) GENCLONE: a computer program to analyse genotypic data, test for clonality and describe spatial clonal organization. Molecular Ecology Notes 7, 15-17.

Arnaud-Haond S, Duarte CM, Alberto F, Serrao EA (2007a) Standardizing methods to address clonality in population studies. Molecular Ecology 16, 5115-5139.

Arnaud-Haond S, Marbà N, Diaz-Almela E, Serrao E, Duarte CM (2010) Comparative analysis of stability-genetic diversity in seagrass (Posidonia oceanica) meadows yields unexpected results. Estuaries and Coasts, DOI 10.1007/s12237-12009-1923812239.

Arnaud-Haond S, Migliaccio M, Diaz-Almela E, et al. (2007b) Vicariance patterns in the Mediterranean Sea: east-west cleavage and low dispersal in the endemic seagrass Posidonia oceanica. Journal of Biogeography 34, 963-976. 
Arnaud-Haond S, Vonau V, Rouxel C, et al. (2008) Genetic structure at different spatial scales in the pearl oyster (Pinctada margaritifera cumingii) in French Polynesian lagoons: beware of sampling strategy and genetic patchiness. Marine Biology 155, $147-157$.

Bahri B, Leconte M, Ouffroukh A, De Vallavieille-Pope C, Enjalbert J (2009) Geographic limits of a clonal population of wheat yellow rust in the Mediterranean region. Molecular Ecology 18, 4165-4179.

Belkhir K, Borsa P, Chikhi L, Raufaste N, Bonhomme F (2004) GENETIX 4.05, logiciel sous Windows TM pour la génétique des populations. Laboratoire Génome, Populations, Interactions, CNRS UMR 5000, Université de Montpellier II, Montpellier

Black WC, Krafsur ES (1985) A FORTRAN program for the calculation and analysis of 2locus linkage disequilibrium coefficients. Theoretical and Applied Genetics 70, 491496.

Booy G, Hendriks RJJ, Smulders MJM, Van Groenendael JM, Vosman B (2000) Genetic diversity and the survival of populations. Plant Biology 2, 379-395.

Camus PA, Lima M (2002) Populations, metapopulations, and the open-closed dilemma: the conflict between operational and natural population concepts. Oikos 97, 433-438.

Chakraborty R, Jin L (1993) Determination of Relatedness between individuals using DNA fingerprinting. Human Biology 65, 875-895.

Churchill AC, Nieves G, Brenowitz AH (1985) Flotation and dispersal of eelgrass seeds by gas-bubbles. Estuaries 8, 352-354.

Coyer JA, Diekmann OE, Serrao EA, et al. (2004) Population genetics of dwarf eelgrass Zostera nolti throughout its biogeographic range. Marine Ecology-Progress Series 281, 51-62. 
De Heij H, Nienhuis PH (1992) Intraspecific variation in intraspecific patterns of phenoypically separated populations of Zostera marina in the ZW Netherlands. Journal of Experimental Marine Biology and Ecology 161.

Den Hartog C (1970) The seagrasses of the world. North Holland publishing Company, Amsterdam, 275pp.

Den Hartog C, Hily C (1997) Les herbiers de Zostères : synthèse, menaces et perspectives. Les biocénoses marines et littorales françaises des côtes atlantiques, Manche et Mer du Nord. Dauvin ed M.N.H.N., Paris.

Diaz-Almela E, Arnaud-Haond S, Vliet MS, et al. (2007) Feed-backs between genetic structure and perturbation-driven decline in seagrass (Posidonia oceanica) meadows. Conservation Genetics 8, 1377-1391.

Diekmann OE, Bak RPM, Stam WT, Olsen JL (2001) Molecular genetic evidence for probable reticulate speciation in the coral genus Madracis from a Caribbean fringing reef slope. Marine Biology 139, 221-233.

Doherty PJ, Planes S, Mather P (1995) Gene flow and larval duration in 7 species of fish from the Great-Barrier-Reef. Ecology 76, 2373-2391.

Dorken ME, Eckert CG (2001) Severely reduced sexual reproduction in northern populations of a clonal plant, Decodon verticillatus (Lythraceae). Journal of Ecology 89, 339-350.

Douhovnikoff V, Dodd RS (2003) Intra-clonal variation and a similarity threshold for identification of clones: application to Salix exigua using AFLP molecular markers. Theoretical and Applied Genetics 106, 1307-1315.

Edmands S, Moberg PE, Burton RS (1996) Allozyme and mitochondrial DNA evidence of population subdivision in the purple sea urchin Strongylocentrotus purpuratus. Marine Biology 126, 443-450. 
Ehlers A, Worm B, Reusch TBH (2008) Importance of genetic diversity in eelgrass Zostera marina for its resilience to global warming. Marine Ecology-Progress Series 355, 1-7.

Eriksson O (1993) Dynamics of genets in clonal plants. Trends in Ecology \& Evolution 8, 313-316.

Estoup A, Tailliez C, Cornuet JM, Solignac M (1995) Size homoplasy and mutational processes of interrupted microsatellites in two bee species, Apis mellifera and Bombus terrestris (Apidae). Molecular Biology and Evolution 12, 1074-1084.

Fortuna MA, Popa-Lisseanu AG, Ibanez C, Bascompte J (2009) The roosting spatial network of a bird-predator bat. Ecology 90, 934-944.

Frankham R (2005) Genetics and extinction. Biological Conservation 126, 131-140.

Freeman LC (1977) A Set of Measures of Centrality based on Betweenness. Sociometry 40, $35-41$.

Hall LM, Hanisak MD, Virnstein RW (2006) Fragments of the seagrasses Halodule wrightii and Halophila johnsonii as potential recruits in Indian River Lagoon, Florida. Marine Ecology-Progress Series 310, 109-117.

Harada Y, Kawano S, Iwasa Y (1997) Probability of clonal identity: inferring the relative success of sexual versus clonal reproduction from spatial genetic patterns. Journal of Ecology 85, 591-600.

Harwell MC, Orth RJ (2002) Long-distance dispersal potential in a marine macrophyte. Ecology 83, 3319-3330.

Hedgecock D (1994) Temporal and spatial genetic-structure of marine animal populations in the California current. California Cooperative Oceanic Fisheries Investigations Reports 35, 73-81. 
Hedgecock D, Hutchinson ES, Li G, Sly FL, Nelson K (1994) The central stock of northern anchovy (Engraulis mordax) is not a randomly mating population. California Cooperative Oceanic Fisheries Investigations Reports 35, 121-136.

Hemminga M, Duarte CM (2000) Seagrass Ecology. Cambridge (United Kingdom): Cambridge University Press

Hily C, Bouteille M (1999) Modifications of the specific diversity and feeding guilds in an intertidal sediment colonized by an eelgrass meadow (Zostera marina) (Brittany, France). Comptes Rendus De L Academie Des Sciences Serie Iii-Sciences De La VieLife Sciences 322, 1121-1131.

Hily C, Raffin C, Brun A, den Hartog C (2002) Spatio-temporal variability of wasting disease symptoms in eelgrass meadows of Brittany (France). Aquatic Botany 72, 37-53.

Hughes AR, Stachowicz JJ (2004) Genetic diversity enhances the resistance of a seagrass ecosystem to disturbance. Proceedings of the National Academy of Sciences of the United States of America 101, 8998-9002.

Hughes AR, Stachowicz JJ (2009) Ecological impacts of genotypic diversity in the clonal seagrass Zostera marina. Ecology 90, 1412-1419.

Huston M (1979) General hypothesis of species-diversity. American Naturalist 113, 81-101.

Johannesson K, Johannesson B, Lundgren U (1995) Strong natural selection causes microscale allozyme variation in a marine snail. Proceedings of the National Academy of Sciences of the United States of America 92, 2602-2606.

Johnson MS, Black R (1982) Chaotic Genetic Patchiness in an Intertidal Limpet, Siphonaria sp. Marine Biology 70, 157-164.

Johnson MS, Black R (1984) Pattern beneath the chaos-the effect of recruitment on genetic patchiness in an intertidal limpets. Evolution 38, 1371-1383. 
Johnson MS, Holborn K, Black R (1993) Fine-scale patchiness and genetic heterogeneity of recruits of the corallivorous gasteropod Drupella cornus. Marine Biology 117, 91-96.

Kendall MS, Battista T, Hillis-Starr Z (2004) Long term expansion of a deep Syringodium filiforme meadow in St. Croix, US Virgin Islands: the potential role of hurricanes in the dispersal of seeds. Aquatic Botany 78, 15-25.

Lacson JM, Morizot DC (1991) Temporal genetic variation in subpopulations of bicolor damselfish (Stegastes partitus) inhabiting coral reefs in the Florida keys. Marine Biology 110, 353-357.

Nei M (1978) Estimation of average heterozygosity and genetic distance from a small number of individuals. Genetics 89, 583-590.

Olsen JL, Stam WT, Coyer JA, et al. (2004) North Atlantic phylogeography and large-scale population differentiation of the seagrass Zostera marina L. Molecular Ecology 13, 1923-1941.

Orth RJ, Carruthers TJB, Dennison WC, et al. (2006) A global crisis for seagrass ecosystems. Bioscience 56, 987-996.

Orth RJ, Heck KL, Vanmontfrans J (1984) Faunal communities in seagrass beds. A review of the influence of plant structure and prey characteristics on predator-prey relationships. Estuaries 7, 339-350.

Parks JC, Werth CR (1993) A study of spatial features of clones in a population of bracken fern, Pteridium aquilinum (Dennstaedtiaceae). American Journal of Botany 80, 537544.

Percival SM, Sutherland WJ, Evans PR (1996) A spatial depletion model of the responses of grazing wildfowl to the availability of intertidal vegetation. Journal of Applied Ecology 33, 979-992. 
Pielou EC (1969) An Introduction to Mathematical Ecology. Whiley-Interscience, New-York. Provan J, Wilson S, Portig AA, Maggs CA (2008) The importance of reproductive strategies in population genetic approaches to conservation: an example from the marine angiosperm genus Zostera. Conservation Genetics 9, 271-280.

Reusch TBH (2006) Does disturbance enhance genotypic diversity in clonal organisms? A field test in the marine angiosperm Zostera marina. Molecular Ecology 15, 277-286.

Reusch TBH, Ehlers A, Hammerli A, Worm B (2005) Ecosystem recovery after climatic extremes enhanced by genotypic diversity. Proceedings of the National Academy of Sciences of the United States of America 102, 2826-2831.

Reusch TBH, Stam WT, Olsen JL (1999) Microsatellite loci in eelgrass Zostera marina reveal marked polymorphism within and among populations. Molecular Ecology 8, 317-321.

Reusch TBH, Stam WT, Olsen JL (2000) A microsatellite-based estimation of clonal diversity and population subdivision in Zostera marina, a marine flowering plant. Molecular Ecology 9, 127-140.

Ritland K (1996) Estimators for pairwise relatedness and individual inbreeding coefficients. Genetical Research 67, 175-185.

Roughgarden J, Gaines S, Possingham H (1988) Recruitment dynamics in complex lifecycles. Science 241, 1460-1466.

Rousset F (1997) Genetic differentiation and estimation of gene flow from F-statistics under isolation by distance. Genetics 145, 1219-1228.

Rozenfeld AF, Arnaud-Haond S, Hernandez-Garcia E, et al. (2007) Spectrum of genetic diversity and networks of clonal organisms. Journal of the Royal Society Interface 4, 1093-1102. 
Rozenfeld AF, Arnaud-Haond S, Hernandez-Garcia E, et al. (2008) Network analysis identifies weak and strong links in a metapopulation system. Proceedings of the National Academy of Sciences of the United States of America 105, 18824-18829.

Ruggiero MV, Capone S, Pirozzi P, Reusch TBH, Procaccini G (2005) Mating system and clonal architecture: A comparative study in two marine angiosperms. Evolutionary Ecology 19, 487-499.

Siegel DA, Kinlan BP, Gaylord B, Gaines SD (2003) Lagrangian descriptions of marine larval dispersion. Marine Ecology-Progress Series 260, 83-96.

Stauffer D, Aharony A (1994) Introduction to Percolation Theory. (Taylor \& Francis, London).

Vekemans X, Hardy OJ (2004) New insights from fine-scale spatial genetic structure analyses in plant populations. Molecular Ecology 13, 921-935.

Watts RJ, Johnson MS, Black R (1990) Effects of recruitment on genetic patchiness in the urchin Echinometra mathaei in western Australia. Marine Biology 105, 145-151.

Waycott M, Duarte CM, Carruthers TJB, et al. (2009) Accelerating loss of seagrasses across the globe threatens coastal ecosystems. Proceedings of the National Academy of Sciences of the United States of America 106, 12377-12381.

Weir BS, Cockerham CC (1984) Estimating F-statistics for the analysis of the population structure. Evolution 38, 1358-1370.

Young AG, Hill JH, Murray BG, Peakall R (2002) Breeding system, genetic diversity and clonal structure in the sub-alpine forb Rutidosis leiolepis F. Muell. (Asteraceae). Biological Conservation 106, 71-78. 


\section{Figure legends}

Figure 1 Cartography of the 7 intertidal meadows of Z. marina, studied here. For each location, two quadrats were determined for sample collection (approximately 35 sampling units were taken from each quadrat).

Figure 2 Isolation-by-distance for Z. marina. The dashed line corresponds to the significant regression combining the two distance scales, indicating that pairs within a location are less distinct than pairs among locations. The left-hand full line corresponds to the regression with pairs within a location (local scale), and the right-hand full line to the regression with pairs among locations (regional scale).

Figure 3 Spatial autocorrelation analysis of Z. marina in quadrat 1 of Arradon. (a) clonal structure and subrange. Kinship estimates from all ramet pairs or only for pairs between ramets showing a different multilocus genotype, and probability of clonal identity (proportion of pairs between ramets with identical MLGs), with confidence limits (for $\mathrm{P}=0.975$ and $\mathrm{P}=$ 0.025) based on 1000 permutations of spatial coordinates. (b) A single ramet per multiramet genet was randomly selected to create a 100-genet data file to generate the confidence limits for the correlogram.

(1) 
Figure 4 Network topology of the 7 meadows of Z. marina studied, based on the Shared 816 Alleles Distance between genets. Only links with distances smaller than or equal to the percolation distance $(\mathrm{Dpe}=0.45)$ are presented. For greater readability, nodes representing genets are not arranged according to their geographic coordinates. For each location, genets of quadrat 1 are represented by ellipses and genets of quadrat 2 by boxes. Colors correspond to sampling locations.

Figure S1 Network topologies of Z. marina genets at the local scale, based on the Shared Alleles Distance between genets. Only links with values smaller than or equal to the effective percolation distance (Dpe) are presented. Nodes representing genets of quadrat 1 are represented by ellipses and genets of quadrat 2 by boxes. The color legend is the same as that used in Figure 4. $\mathrm{A}$ = Arradon, $\mathrm{B}=$ Roscanvel, $\mathrm{C}=$ Molène, $\mathrm{D}=$ Sainte-Marguerite, $\mathrm{E}=$ Callot, $\mathrm{F}=$ Arcouest, $\mathrm{G}=$ Saint-Malo. 


\begin{tabular}{|c|c|c|c|c|c|}
\hline Site & Quadrate & $\begin{array}{c}\text { Number of } \\
\text { SU }\end{array}$ & Latitude & Longitude & $\begin{array}{l}\text { Distance } \\
\text { (meters) }\end{array}$ \\
\hline \multirow{2}{*}{ Saint-Malo } & $\mathrm{Q} 1$ & 35 & $48^{\circ} 38^{\prime} 923 \mathrm{~N}$ & $02^{\circ} 01^{\prime} 992 \mathrm{~W}$ & \multirow{2}{*}{85} \\
\hline & Q2 & 35 & $48^{\circ} 38^{\prime} 958 \mathrm{~N}$ & $02^{\circ} 02^{\prime} 038 \mathrm{~W}$ & \\
\hline \multirow{2}{*}{ L'Arcouest } & Q1 & 34 & $48^{\circ} 49^{\prime} 428 \mathrm{~N}$ & $03^{\circ} 01^{\prime} 162 \mathrm{~W}$ & \multirow{2}{*}{70} \\
\hline & Q2 & 34 & $48^{\circ} 49^{\prime} 425 \mathrm{~N}$ & $03^{\circ} 01^{\prime} 218 \mathrm{~W}$ & \\
\hline \multirow{2}{*}{ Callot } & Q1 & 35 & $48^{\circ} 41^{\prime} 064 \mathrm{~N}$ & $03^{\circ} 54^{\prime} 968 \mathrm{~W}$ & \multirow{2}{*}{30} \\
\hline & Q2 & 35 & $48^{\circ} 41^{\prime} 052 \mathrm{~N}$ & $03^{\circ} 54^{\prime} 982 \mathrm{~W}$ & \\
\hline \multirow{2}{*}{$\begin{array}{c}\text { Sainte- } \\
\text { Marguerite }\end{array}$} & Q1 & 35 & $48^{\circ} 35^{\prime} 811 \mathrm{~N}$ & $04^{\circ} 37^{\prime} 389 \mathrm{~W}$ & \multirow{2}{*}{75} \\
\hline & Q2 & 35 & $48^{\circ} 35^{\prime} 830 \mathrm{~N}$ & $04^{\circ} 37^{\prime} 443 \mathrm{~W}$ & \\
\hline Molène & Q1 & $32(12)$ & $48^{\circ} 23^{\prime} 760 \mathrm{~N}$ & $04^{\circ} 56^{\prime} 934 \mathrm{~W}$ & - \\
\hline \multirow{2}{*}{ Roscanvel } & Q1 & 35 & $48^{\circ} 19^{\prime} 934 \mathrm{~N}$ & $04^{\circ} 32^{\prime} 209 \mathrm{~W}$ & \multirow{2}{*}{100} \\
\hline & Q2 & 35 & $48^{\circ} 19^{\prime} 984 \mathrm{~N}$ & $04^{\circ} 32^{\prime} 182 \mathrm{~W}$ & \\
\hline \multirow{2}{*}{ Arradon } & Q1 & 34 & $47^{\circ} 36^{\prime} 911 \mathrm{~N}$ & $02^{\circ} 49^{\prime} 636 \mathrm{~W}$ & \multirow{2}{*}{80} \\
\hline & Q2 & 35 & $47^{\circ} 36^{\prime} 914 \mathrm{~N}$ & $02^{\circ} 49^{\prime} 574 \mathrm{~W}$ & \\
\hline
\end{tabular}

833

\section{Tables} SU. The inter-quadrat distances were calculated with GPS coordinates.

.
0.001 .

Table 1 Locations, correspondence with the points surveyed by REBENT network and number of sampling units (SU). For Molène, we also give the number of haphazardly-sampled

Table 2 Parameters of clonal structure: for each quadrat; samples were standardized with 30 ramets. G: number of identified MLLs. R: clonal richness. D* and ED*: Simpson index and its equitability index. $\beta$ : slope of Pareto distribution. Grey cells indicate values calculated following a procedure of minimal estimation. CR: clonal subrange. Parameters of genetic composition: the two parameters we assessed were heterozygosity and allelic richness. $\mathrm{H}_{\mathrm{e}}$ : expected heterozygosity without bias (Nei, 1978); $\mathrm{H}_{0}$ : observed heterozygosity. $\mathrm{F}_{\text {IS }}$ and LD values were estimated after 1000 permutations of alleles within the quadrat. The mean number of alleles per locus Â was also estimated. Grey values: ns; * : p $<0.05 ;{ }^{* *}: \mathrm{p}<0.01$; $^{* * *}$ : $\mathrm{p}<$ 


\begin{tabular}{|c|c|c|c|c|c|c|c|c|c|c|c|c|c|}
\hline \multirow{2}{*}{ Meadow } & \multirow{2}{*}{ quadrate } & \multirow[b]{2}{*}{$\mathbf{N}$} & \multirow[b]{2}{*}{ G } & \multicolumn{5}{|c|}{ clonal structure } & \multicolumn{5}{|c|}{ genetic composition } \\
\hline & & & & $\mathbf{R}$ & $\mathbf{D}^{*}$ & ED* & $\beta$ & $\mathbf{C R}$ & He & Ho & Fis & $\hat{\mathbf{A}}$ & LD \\
\hline \multirow[t]{2}{*}{ Arradon } & Q1 & 30 & 26 & 0.86 & 0.99 & 0.65 & 3.10 & 5.59 & 0.52 & 0.51 & 0.03 & 5.89 & 0.06 \\
\hline & Q2 & 30 & 21 & 0.69 & 0.97 & 0.86 & 2.09 & 14.56 & 0.54 & 0.52 & 0.03 & 6.00 & 0.00 \\
\hline \multirow[t]{2}{*}{ Roscanvel } & Q1 & 30 & 30 & 1.00 & 1.00 & - & 4.95 & 0.00 & 0.52 & 0.51 & 0.01 & 4.78 & 0.06 \\
\hline & Q2 & 30 & 21 & 0.69 & 0.97 & 0.88 & 2.40 & 12.04 & 0.50 & 0.52 & -0.05 & 4.11 & 0.03 \\
\hline Molène & Q1 & 30 & 15 & 0.48 & 0.85 & 0.51 & 1.36 & - & 0.40 & 0.40 & 0.01 & 3.44 & 0.05 \\
\hline \multirow[t]{2}{*}{ Sainte-Marguerite } & Q1 & 30 & 28 & 0.93 & 1.00 & 0.52 & 3.97 & 2.50 & 0.54 & 0.50 & $0.08^{*}$ & 6.67 & 0.50 \\
\hline & Q2 & 30 & 28 & 0.93 & 0.99 & 0.00 & 4.01 & 3.04 & 0.69 & 0.60 & $0.14 * * *$ & 9.67 & 0.58 \\
\hline \multirow[t]{2}{*}{ Callot } & Q1 & 30 & 26 & 0.86 & 0.99 & 0.65 & 2.89 & 5.32 & 0.46 & 0.42 & $0.08^{*}$ & 5.78 & 0.06 \\
\hline & Q2 & 30 & 23 & 0.76 & 0.98 & 0.85 & 3.00 & 7.76 & 0.45 & 0.44 & 0.03 & 4.89 & 0.08 \\
\hline \multirow[t]{2}{*}{ l'Arcouest } & Q1 & 30 & 19 & 0.62 & 0.91 & 0.45 & 1.46 & 17.01 & 0.41 & 0.46 & $-0.13^{*}$ & 4.11 & 0.04 \\
\hline & Q2 & 30 & 30 & 1.00 & 1.00 & - & 4.95 & 0.00 & 0.40 & 0.45 & $-0.12^{* *}$ & 3.89 & 0.07 \\
\hline \multirow[t]{2}{*}{ Saint-Malo } & Q1 & 30 & 19 & 0.62 & 0.95 & 0.80 & 2.05 & 18.61 & 0.29 & 0.35 & $-0.21^{* *}$ & 2.33 & 0.07 \\
\hline & Q2 & 30 & 15 & 0.48 & 0.89 & 0.70 & 1.54 & 10.20 & 0.40 & 0.39 & 0.04 & 3.56 & 0.00 \\
\hline
\end{tabular}

845

846 Table 3 Matrix of genetic distance $\left(\mathrm{F}_{\mathrm{ST}}\right)$ and geographic distance (kilometers). The

847 geographic distance is expressed in kilometers and ranged from $0.03 \mathrm{~km}$ for the two quadrats

848 at Callot to 442km between Saint-Malo and Arradon. Fst values are calculated following

849 Weir\&Cockerham (1984), for each pair of samples. Grey values: $\mathrm{p}<0.05$. All other values are significant with a probability $\mathrm{p}<0.01$.

\begin{tabular}{ccccccccccccccc}
\hline & & Arr 1 & Arr 2 & Ros 1 & Ros 2 & Mol & SMar 1 & SMar 2 & Cal 1 & Cal 2 & Arc 1 & Arc 2 & SMal 1 & SMal 2 \\
\hline \multirow{2}{*}{ Arradon } & Q1 & - & 0.08 & 0.15 & 0.13 & 0.22 & 0.30 & 0.24 & 0.08 & 0.12 & 0.17 & 0.19 & 0.19 & 0.14 \\
& Q2 & 0.08 & - & 0.14 & 0.13 & 0.25 & 0.28 & 0.21 & 0.12 & 0.06 & 0.13 & 0.13 & 0.21 & 0.14 \\
\multirow{5}{*}{ Roscanvel } & Q1 & 195 & 195 & - & 0.02 & 0.23 & 0.21 & 0.17 & 0.10 & 0.15 & 0.12 & 0.13 & 0.19 & 0.09 \\
& Q2 & 195 & 195 & 0.1 & - & 0.24 & 0.23 & 0.20 & 0.09 & 0.14 & 0.13 & 0.14 & 0.23 & 0.11 \\
Molène & Q1 & 198 & 198 & 33 & 33 & - & 0.14 & 0.14 & 0.14 & 0.28 & 0.28 & 0.33 & 0.28 & 0.22 \\
Sainte-Marguerite & Q1 & 239 & 239 & 35 & 35 & 41 & - & 0.02 & 0.22 & 0.29 & 0.25 & 0.28 & 0.32 & 0.22 \\
& Q2 & 239 & 239 & 35 & 35 & 41 & 0.08 & - & 0.20 & 0.24 & 0.20 & 0.23 & 0.25 & 0.17 \\
\multirow{5}{*}{ Callot } & Q1 & 299 & 299 & 134 & 134 & 101 & 60 & 60 & - & 0.12 & 0.10 & 0.16 & 0.10 & 0.04 \\
& Q2 & 299 & 299 & 134 & 134 & 101 & 60 & 60 & 0.03 & - & 0.11 & 0.07 & 0.19 & 0.12 \\
l'Arcouest & Q1 & 367 & 367 & 202 & 202 & 169 & 128 & 128 & 68 & 68 & - & 0.06 & 0.14 & 0.06 \\
& Q2 & 367 & 367 & 202 & 202 & 169 & 128 & 128 & 68 & 68 & 0.07 & - & 0.17 & 0.10 \\
Saint-Malo & Q1 & 442 & 442 & 277 & 277 & 244 & 203 & 203 & 143 & 143 & 75 & 75 & - & 0.07 \\
& $\mathbf{Q 2}$ & 442 & 442 & 277 & 277 & 244 & 203 & 203 & 143 & 143 & 75 & 75 & 0.085 & - \\
\hline
\end{tabular}



corresponds to the average value of $C C$ inside local networks.

\begin{tabular}{lcc}
\hline & BC $(* 1000)$ & CC \\
\hline Arradon & 0.73 & 0.42 \\
Roscanvel & 5.93 & 0.17 \\
Molène & 5.03 & 0.33 \\
Sainte-Marguerite & 6.02 & 0.16 \\
Callot & 2.68 & 0.33 \\
Arcouest & 5.15 & 0.31 \\
Saint-Malo & 9.95 & 0.52 \\
Average & 4.9 & 0.32 \\
\hline
\end{tabular}

859

Fig.1

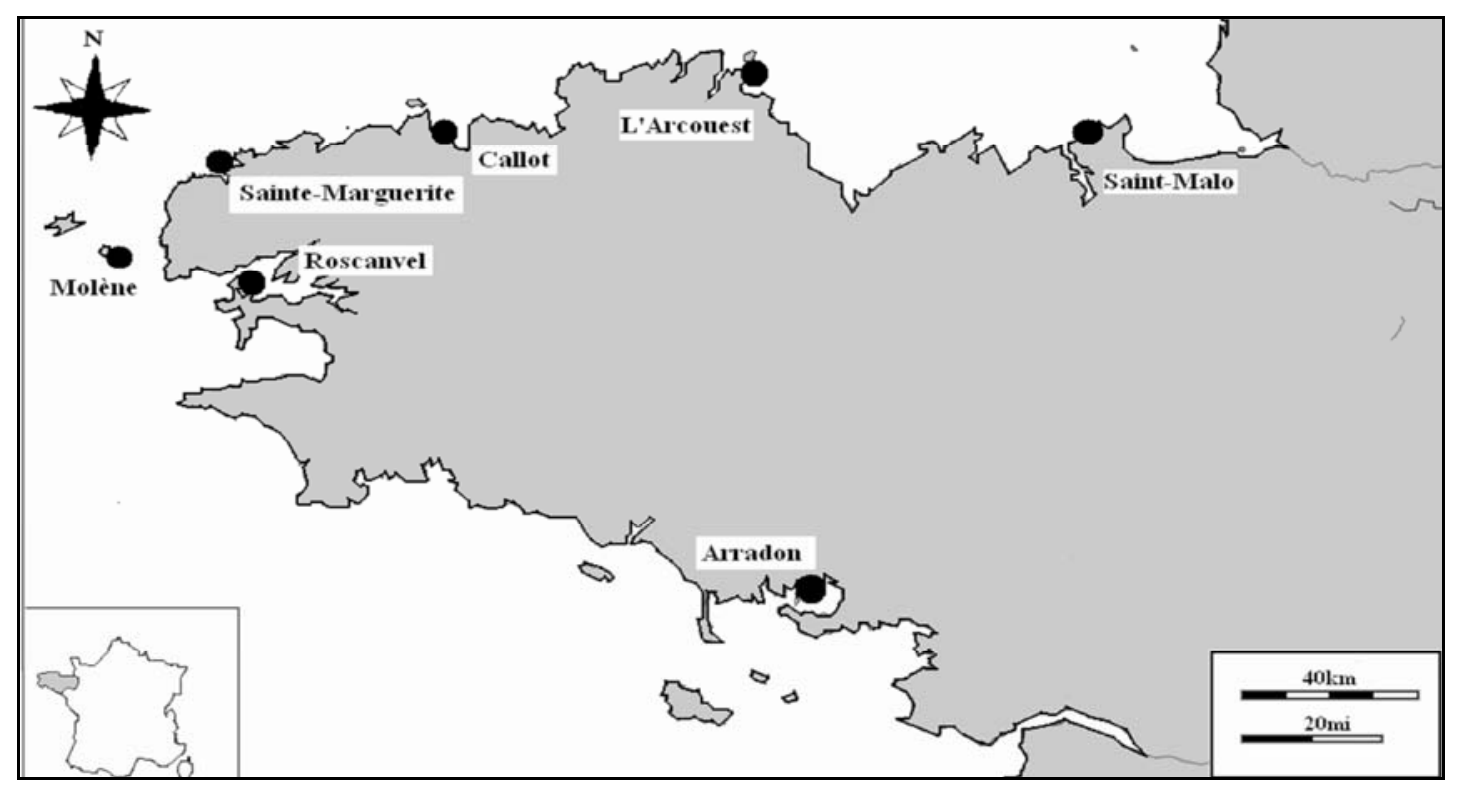

Fig. 2 


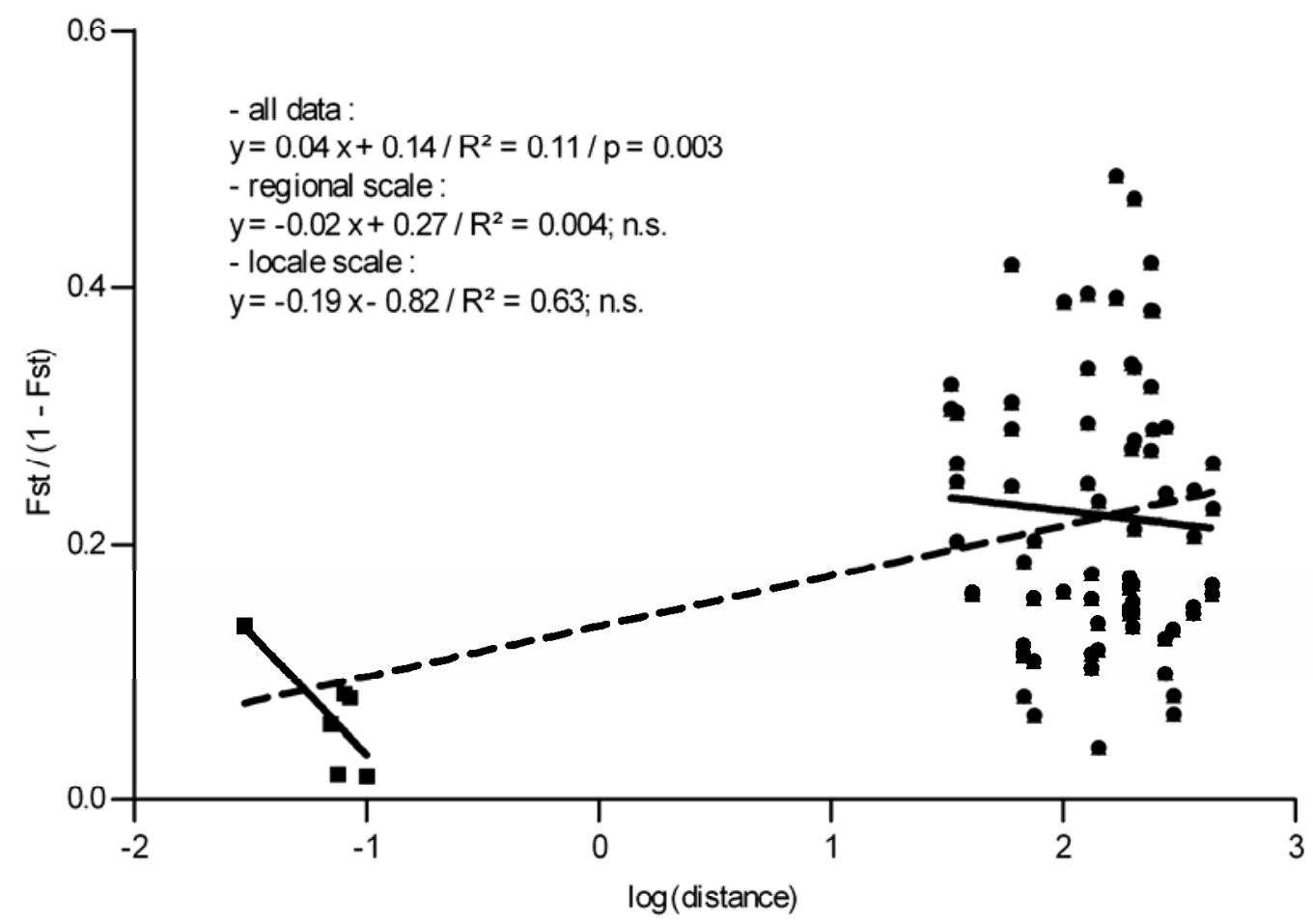

864

865

Fig. 3
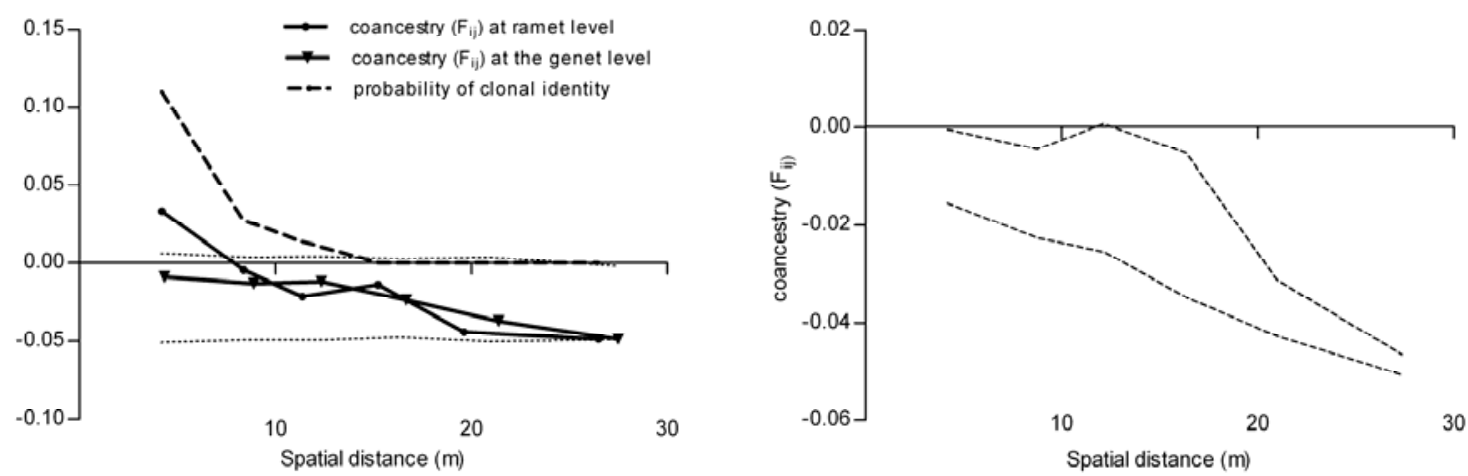

867

868

869

870 


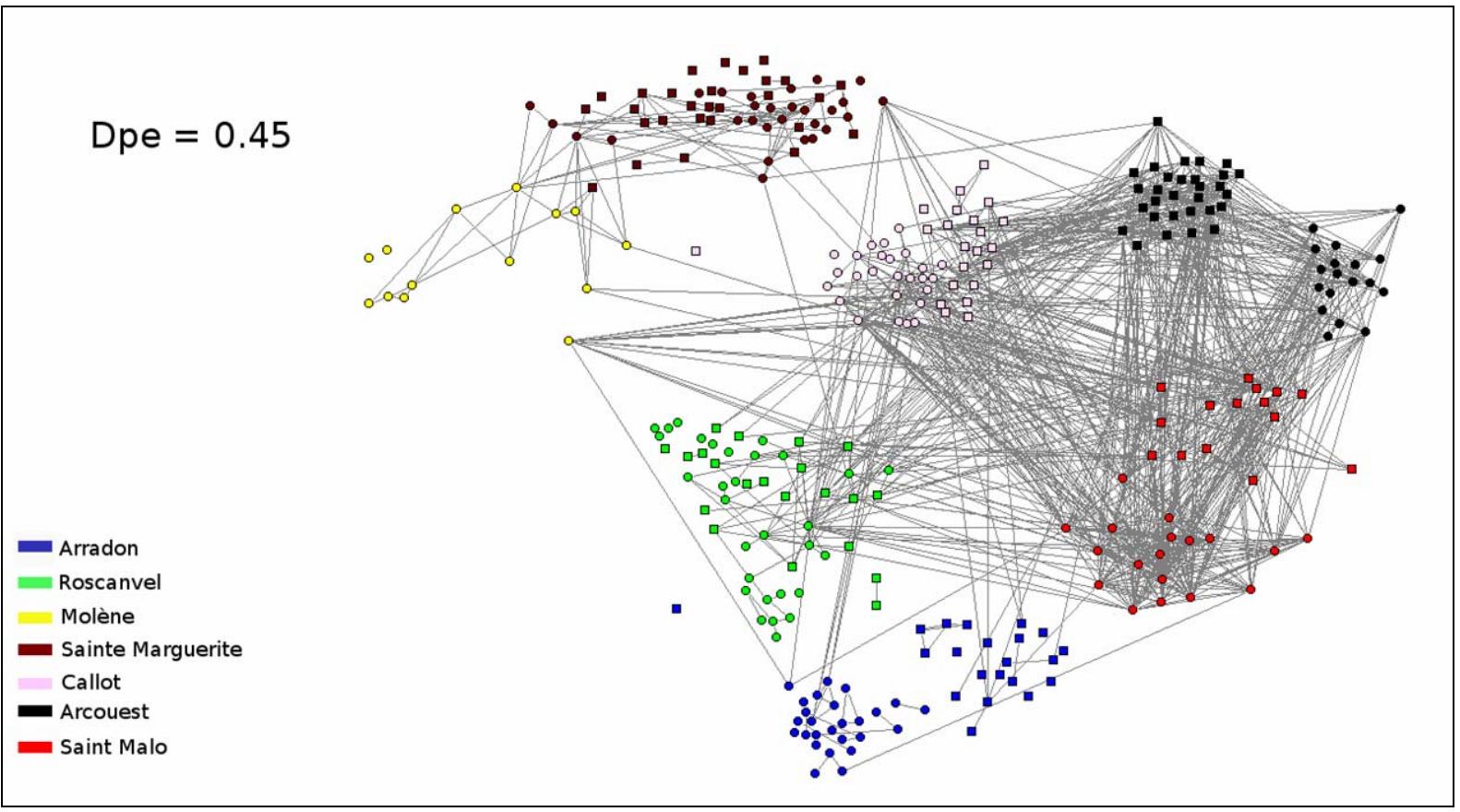

874
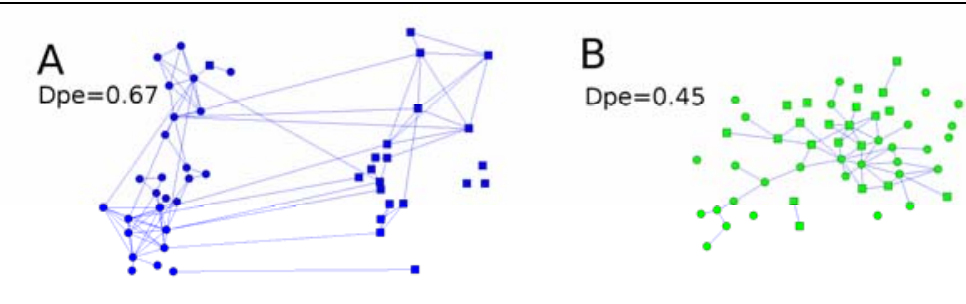

C

Dpe $=0.45$

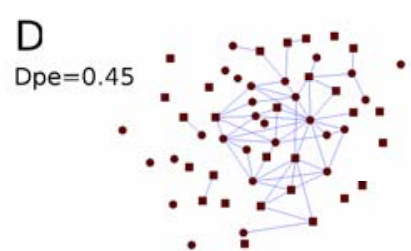

E

Dpe $=0.45$
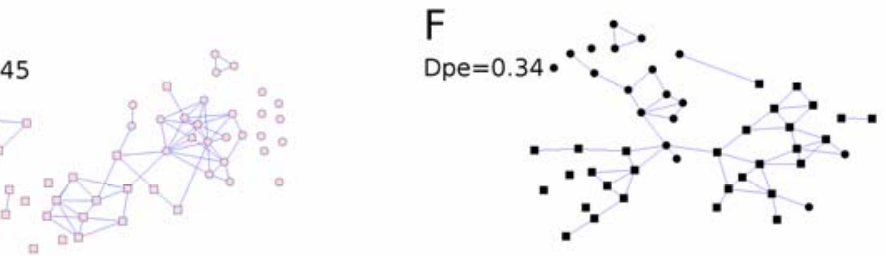

G

Dpe $=0.34$

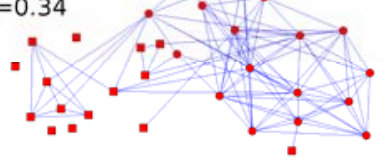

